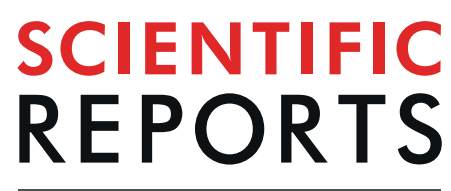

natureresearch

\title{
Early decrease in erector spinae muscle area and future risk of mortality in idiopathic pulmonary fibrosis
}

\begin{abstract}
Akiko Nakano ${ }^{1}{ }^{1}$, Hirotsugu Ohkubo ${ }^{1 *}$, Hiroyuki Taniguchi ${ }^{2}$, Yasuhiro Kondoh ${ }^{2}$, Toshiaki Matsuda ${ }^{2}$, Mitsuaki Yagi ${ }^{3}$, Taiki Furukawa ${ }^{4}$, Yoshihiro Kanemitsu ${ }^{1}$ \& Akio Niimi $^{1}$

Computed tomography (CT) assessment of the cross-sectional area of the erector spinae muscles $\left(E S M_{C S A}\right)$ can be used to evaluate sarcopenia and cachexia in patients with lung diseases. This study aimed to confirm whether serial changes in $\mathrm{ESM}_{\mathrm{CSA}}$ are associated with survival in patients with idiopathic pulmonary fibrosis (IPF). Data from consecutive patients with IPF who were referred to a single centre were retrospectively reviewed. We measured the $\mathrm{ESM}_{\mathrm{CSA}}$ at the level of the 12 th thoracic vertebra on CT images at referral and 6 months later $(n=119)$. The follow-up time was from 817-1633 days (median, 1335 days) and 59 patients (49.6\%) died. A univariate Cox regression analysis showed that the decline in \% predicted forced vital capacity (FVC) (Hazard ratios [HR] 1.041, 95\% confidence interval $[\mathrm{Cl}] 1.013-1.069, \mathrm{P}=0.004)$, the decline in body mass index (BMI) $(\mathrm{HR} 1.084,95 \% \mathrm{Cl} 1.037-$ $1.128 ; \mathrm{P}<0.001)$ and that in $\mathrm{ESM}_{C S A}(\mathrm{HR} 1.057,95 \% \mathrm{Cl} 1.027-1.086 ; \mathrm{P}<0.001)$ were prognostic factors. For multivariate analyses, the decline in $\operatorname{ESM}_{\mathrm{CSA}}(\mathrm{HR} 1.039,95 \% \mathrm{Cl} 1.007-1.071, \mathrm{P}=0.015)$ was a significant prognostic factor, while those in \% FVC and BMI were discarded. Early decrease in ESM CSA $_{\text {. }}$ may be a useful predictor of prognosis in patients with IPF.
\end{abstract}

Idiopathic pulmonary fibrosis (IPF) is a fibrotic pulmonary disease which leads to the death of most patients ${ }^{1,2}$. The prognosis for IPF patients is poor at 3 to 4 years $^{1-4}$. The disease is characterised by decreased lung volumes and reduced gas exchange, and it is associated with symptoms of progressive dyspnoea, cough and reduced exercise capacity. Several prognostic factors for IPF are known, including dyspnoea score, pulmonary function, oxygen desaturation during exercise, and fibrotic changes on high resolution computed tomography (HRCT) ${ }^{5}$. Other prognostic factors have been reported, such as pathological findings $s^{6,7}$, serum biomarkers ${ }^{8,9}$, St. George's Respiratory Questionnaire score ${ }^{10}$, fibrosis score ${ }^{11}$, normal lung volume on $\mathrm{HRCT}^{12,13}$ and mean pulmonary arterial pressure ${ }^{14}$. Among pulmonary function variables, a decline in forced vital capacity (FVC) is widely known as a prognostic factor ${ }^{15,16}$.

Cachexia is a complex metabolic syndrome. It is associated with underlying diseases and is characterised by loss of muscle with or without loss of fat mass in cancer and chronic diseases such as congestive heart failure, chronic kidney disease and chronic obstructive pulmonary disease (COPD $)^{17,18}$. Loss of skeletal muscle in cancer patients can potentially be due to anorexia and early satiety, reduced muscle protein synthesis, and/or increased muscle protein breakdown ${ }^{19}$. Sarcopenia is a syndrome characterised by a progressive and generalised loss of skeletal muscle mass and strength, and it carries a risk of poor outcomes such as physical disability, poor quality of life and death ${ }^{20}$.

Assessment of the cross-sectional area of the erector spinae muscles $\left(\mathrm{ESM}_{\mathrm{CSA}}\right)$ from chest computed tomography (CT) scans has been used to evaluate sarcopenia and cachexia in patients with chronic lung disease $\mathrm{e}^{21,22}$. Compared with healthy individuals, $\mathrm{ESM}_{\mathrm{CSA}}$ is decreased in patients with IPF, idiopathic pleuroparenchymal fibroelastosis (iPPEE) and chronic obstructive pulmonary disease (COPD) $)^{21,22}$. $\mathrm{ESM}_{\mathrm{CSA}}$ assessed by chest CT is

${ }^{1}$ Department of Respiratory Medicine, Allergy and Clinical Immunology, Nagoya City University Graduate School of Medical Sciences, Nagoya, Japan. ${ }^{2}$ Department of Respiratory Medicine and Allergy, Tosei General Hospital, Nagoya, Japan. ${ }^{3}$ Department of Respiratory Medicine, National Hospital Organization Higashinagoya National Hospital, Nagoya, Japan. ${ }^{4}$ Department of Respiratory Medicine, Nagoya University Graduate School of Medicine, Nagoya, Japan. *email: hohkubo@med.nagoya-cu.ac.jp 


\begin{tabular}{|c|c|c|}
\hline Variable & 0 month & After 6 months \\
\hline Total, n & 119 & 119 \\
\hline Age, years & $67.0[61.0-71.0]$ & \\
\hline Sex, Female, n (\%) & $21(17.6 \%)$ & \\
\hline Never smoker, n (\%) & $25(21.0 \%)$ & \\
\hline Ex-smoker, n (\%) & $81(68.1 \%)$ & \\
\hline Current smoker, n (\%) & $13(10.9 \%)$ & \\
\hline Smoking history, pack-years & $36.0[5.0-55.5]$ & \\
\hline Body mass index, $\mathrm{kg} / \mathrm{m}^{2}$ & $23.4[21.7-25.2]$ & $23.1[21.4-25.4]$ \\
\hline Biopsy-proven IPF, n (\%) & $62(52.1 \%)$ & \\
\hline FVC, $\%$ predicted & $84.2[70.4-96.5]$ & $78.1[67.5-96.3]$ \\
\hline $\mathrm{FEV}_{1} / \mathrm{FVC}, \%$ & $85.8[81.3-90.6]$ & $86.2[79.7-90.7]$ \\
\hline $\mathrm{DL}_{\mathrm{CO}}, \%$ predicted $*$ & $60.7[48.8-76.7]$ & $58.6[45.3-69.6]$ \\
\hline Distance walked during 6MWT, m & $589[524-645]$ & \\
\hline Lowest $\mathrm{SpO}_{2}$ during $6 \mathrm{MWT}, \%$ & $85.0[80.0-89.0]$ & \\
\hline $\mathrm{ESM}_{\mathrm{CSA},} \mathrm{cm}^{2}$ & $34.2[27.7-40.0]$ & $31.6[25.0-37.0]$ \\
\hline
\end{tabular}

Table 1. Characteristics and $\mathrm{ESM}_{\mathrm{CSA}}$ of patients available for CT after 6 months. Data are presented as median [interquartile range] or $\mathrm{n}(\%)$. Abbreviations: FVC, forced vital capacity; FEV1, forced expiratory volume in 1.0 second; DLCO, diffuse capacity of the lung for carbon monoxide; 6MWT, 6-minute walk test; SpO2, percutaneous oxygen saturation; ESMCSA, cross-sectional area of elector spine muscles. *We analysed using $\mathrm{n}=114$, because 5 cases were missing.

an independent prognostic factor for patients with $\mathrm{COPD}^{21}$. Miller et al. reported that height-adjusted $\mathrm{ESM}_{\mathrm{CSA}}$ was significantly associated with 30-day mortality and length of hospital stay after lobectomy in patients with lung cancer $^{23}$. Suzuki et al. also revealed that a smaller $\mathrm{ESM}_{\mathrm{CSA}}$ in patients with IPF was associated with a poor prognosis $^{22}$.

We queried whether the survival of patients with IPF decreases with a decrease in muscle mass. Resultantly, we hypothesised that a relative decline in $\mathrm{ESM}_{\mathrm{CSA}}$ over the course of 6 months is associated with decreased survival in patients with IPF. We measured the $\mathrm{ESM}_{\mathrm{CSA}}$ at the level of the spinous process of 12 th thoracic vertebra on CT images at baseline $(\mathrm{n}=144)$ and 6 months later $(\mathrm{n}=119)$ in patients with IPF.

\section{Results}

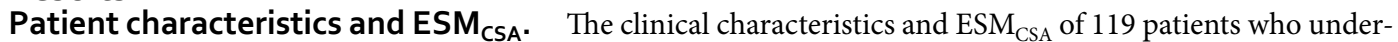
went HRCT after 6 months are shown in Table 1. The baseline $\mathrm{ESM}_{\mathrm{CSA}}$ was 34.2 [27.7-40.0] $\mathrm{cm}^{2}$ whereas $\mathrm{ESM}_{\mathrm{CSA}}$ after 6 months was $31.6[25.0-37.0] \mathrm{cm}^{2}$.

The correlation of $\mathrm{ESM}_{\mathrm{CSA}}$ values in the 119 patients between trained individuals were as follows; $\mathrm{r}=0.951$ (95\% confidence intervals $[\mathrm{CI}]$ 0.913-0.965), $\mathrm{P}<0.001$. The Bland-Altman analysis revealed that the agreement between two individuals was excellent (0.934).

The clinical characteristics and $\mathrm{ESM}_{\mathrm{CSA}}$ of 144 patients at baseline, 119 patients who underwent HRCT after 6 months, and 25 patients who did not undergo HRCT after 6 months are shown in Supplemental Table 1. We could not analyse CT in 25 patients after 6 months. Eleven of the 25 patients died; 5 were transferred; 3 were unchanged in pulmonary function test; 2 were out of timing; 1 was rejected; and 1 experienced acute exacerbation. There were significant differences in age $(\mathrm{P}=0.001)$, body mass index $(\mathrm{BMI})(\mathrm{P}=0.039), \% \mathrm{FVC}(\mathrm{P}<0.001), \%$ deffuse capacity of the lung for carbon monoxide $\left(\mathrm{DL}_{\mathrm{CO}}\right)(\mathrm{P}=0.008)$, distance walked during the 6 minute walk test (6MWT) $(\mathrm{P}<0.001)$, lowest $\mathrm{SpO}_{2}$ during the $6 \mathrm{MWT}(\mathrm{P}=0.046)$ and $\mathrm{ESM}_{\mathrm{CSA}}(\mathrm{P}=0.009)$ between patients who underwent HRCT after 6 months and those who did not.

The distributions of $\mathrm{ESM}_{\mathrm{CSA}}$ declines. The distribution of the relative decline in $\mathrm{ESM}_{\mathrm{CSA}}$ is shown in Fig. 1. We compared the relative decline in $\% \mathrm{FVC}$ with that in $\mathrm{ESM}_{\mathrm{CSA}}$ to determine which was greater. We observed that the relative decline in $\mathrm{ESM}_{\mathrm{CSA}}(6.2[0.5-11.8] \%)$ was significantly greater than that in \% FVC $(1.4$ $[-3.1 \%-5.0] \%$ ) (Student's t-test, $\mathrm{P}<0.001)$.

Correlations between the decline in $\mathrm{ESM}_{\mathrm{CSA}}$ and other clinical parameters. The correlations between the relative decline in $\mathrm{ESM}_{\mathrm{CSA}}$ and other clinical parameters were as follows (Table 2); baseline \%FVC $(\mathrm{r}=-0.285$ [-0.464- -0.089], $\mathrm{P}=0.002)$, lowest $\mathrm{SpO}_{2}$ during $6 \mathrm{MWT}(\mathrm{r}=-0.290[-0.458--0.108], \mathrm{P}=0.002)$, the relative decline in \%FVC $(\mathrm{r}=0.202$ [0.022-0.358], $\mathrm{P}=0.028)$, and the relative decline in BMI $(\mathrm{r}=0.394$ [0.217-0.552], $\mathrm{P}<0.001)$. Figure 2 shows the correlations of relative decline in $\mathrm{ESM}_{\mathrm{CSA}}$ with the relative decline in $\% \mathrm{FVC}$, the relative decline in $\% \mathrm{DL}_{\mathrm{CO}}$, and the relative decline in $\mathrm{BMI}$.

The $\mathrm{ESM}_{\mathrm{CSA}}$ at baseline in 144 patients was $33.3[25.9-39.1] \mathrm{cm}^{2}$. The correlations between the $\mathrm{ESM}_{\mathrm{CSA}}$ at baseline and other clinical parameters are shown in Supplemental Table 2.

Prognostic survey. Fifty-nine of 119 patients (49.6\%) died during the study period. The follow-up time of 119 patients was 1335 [817-1633] days. Four cases were lost to follow-up. 


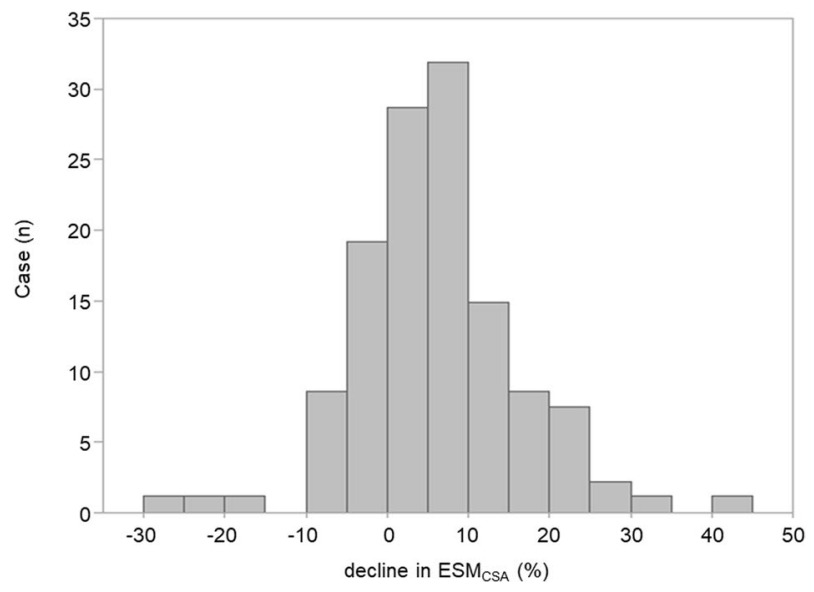

Figure 1. The distribution histogram of the decline in $\mathrm{ESM}_{\mathrm{CSA}}$. The horizontal axis represents the relative decline in $\mathrm{ESM}_{\mathrm{CSA}}$ and the vertical axis represents the number of patients.

(A)

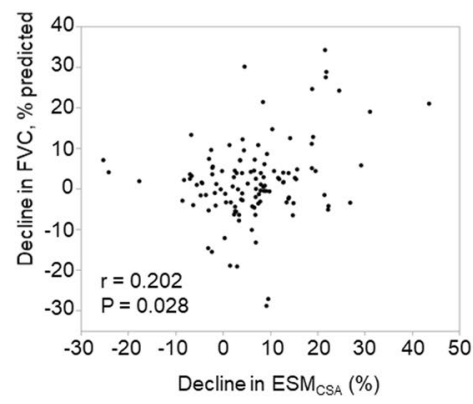

(B)

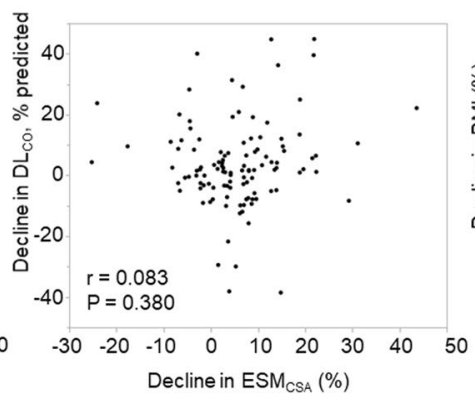

(C)

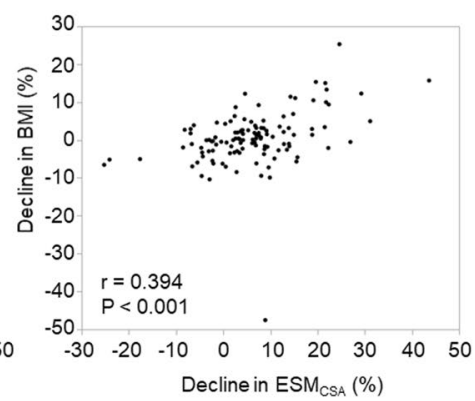

Figure 2. The correlations of decline in $\mathrm{ESM}_{\mathrm{CSA}}$ with declines in $\mathrm{FVC}, \mathrm{DL} \mathrm{CO}_{\mathrm{CO}}$ and $\mathrm{BMI}$. The correlations of relative decline in $\mathrm{ESM}_{\mathrm{CSA}}$ with relative declines in $\mathrm{FVC}(\mathbf{A}), \mathrm{DL}_{\mathrm{CO}}(\mathbf{B})$ and $\mathrm{BMI}(\mathbf{C})$ are shown.

\begin{tabular}{|c|c|c|c|}
\hline Variables & $r$ & 95\%CI & P-value \\
\hline Age, year & -0.044 & $-0.244-0.156$ & 0.637 \\
\hline Baseline body mass index, $\mathrm{kg} / \mathrm{m}^{2}$ & -0.175 & $-0.357-0.020$ & 0.057 \\
\hline Baseline FVC, \% predicted & -0.285 & $-0.464--0.089$ & 0.002 \\
\hline Baseline $\mathrm{FEV}_{1} / \mathrm{FVC}$, \% & 0.187 & $-0.009-0.369$ & 0.042 \\
\hline Baseline $\mathrm{DL}_{\mathrm{CO}}, \%$ predicted & -0.172 & $-0.337-0.017$ & 0.063 \\
\hline Baseline distance walked during $6 \mathrm{MWT}, \mathrm{m}$ & -0.171 & $-0.341-0.019$ & 0.064 \\
\hline Baseline lowest $\mathrm{SpO}_{2}$ during 6MWT, \% & -0.290 & $-0.458--0.101$ & 0.002 \\
\hline Relative decline in FVC, $\%$ & 0.202 & $0.022-0.358$ & 0.028 \\
\hline Relative decline in $\mathrm{DL}_{\mathrm{CO}}$, \%* & 0.083 & $-0.096-0.267$ & 0.377 \\
\hline Relative decline in body mass index, $\%$ & 0.394 & $0.217-0.552$ & $<0.001$ \\
\hline
\end{tabular}

Table 2. Correlations between the decline in the $\mathrm{ESM}_{\mathrm{CSAs}}$ and clinical parameters. Abbreviations: ESMCSA; cross-sectional areas of elector spine muscles; FVC, forced vital capacity; FEV1, forced expiratory volume in 1.0 second; DLCO, diffuse capacity of the lung for carbon monoxide; 6MWT, 6-minute walk test; SpO2, percutaneous oxygen saturation. *We analysed using $n=114$ because 5 cases were missing.

Uni- and multivariate Cox regression analyses. Hazard ratios (HRs) and 95\% CIs in the cohort that was available for 6 months of follow-up $(n=119)$ on univariate and multivariate Cox regression analyses are shown in Table 3. The univariate Cox regression analysis showed that the relative decline in BMI (HR 1.084, 95\% CI 1.037-1.128, P < 0.001), the relative decline in \% FVC (HR 1.041, 95\% CI 1.013-1.069, P=0.004), and the relative decline in $\mathrm{ESM}_{\mathrm{CSA}}(\mathrm{HR} 1.057,95 \% \mathrm{CI} 1.027-1.086, \mathrm{P}<0.001)$ were prognostic factors. On multivariate analyses, the relative decline in $\mathrm{ESM}_{\mathrm{CSA}}(\mathrm{HR} 1.039,95 \% \mathrm{CI} 1.007-1.071, \mathrm{P}=0.015)$ was a significant prognostic 


\begin{tabular}{|l|l|l|l|}
\hline Predictor & HR & $95 \%$ CI & P-value \\
\hline Univariate analysis & 0.994 & $0.964-1.028$ & 0.749 \\
\hline Age & 0.602 & $0.263-1.203$ & 0.185 \\
\hline Sex, female & 1.084 & $1.037-1.128$ & $<0.001$ \\
\hline Relative decline in body mass index, \% & 1.041 & $1.013-1.069$ & 0.004 \\
\hline Relative decline in FVC, \% predicted & 1.013 & $0.991-1.034$ & 0.248 \\
\hline Relative decline in $\mathrm{DL}_{\mathrm{CO}} \%$ predicted\% & 1.057 & $1.027-1.086$ & $<0.001$ \\
\hline Relative decline in $\mathrm{ESM}_{\mathrm{CSA}}, \%$ & 1.036 & $0.986-1.088$ & 0.163 \\
\hline Multivariate analysis & 1.021 & $0.992-1.050$ & 0.155 \\
\hline Relative decline in body mass index, \% & 1.039 & $1.007-1.071$ & 0.015 \\
\hline Relative decline in $\mathrm{FVC} \%$ predicted & & & \\
\hline Relative decline in $\mathrm{ESM}_{\mathrm{CSA}}$ \% &
\end{tabular}

Table 3. Prediction of mortality by uni- and multivariate Cox-proportion analyses in the patients available for CT after 6 months $(n=119)$. Abbreviations: HR, hazard ratio; CI, confidence interval; FVC, forced vital capacity; DLCO, diffuse capacity of the lung for carbon monoxide; ESMCSA, cross-sectional area of erector spinae muscles. *We analysed using $\mathrm{n}=114$, because 5 cases were missing.

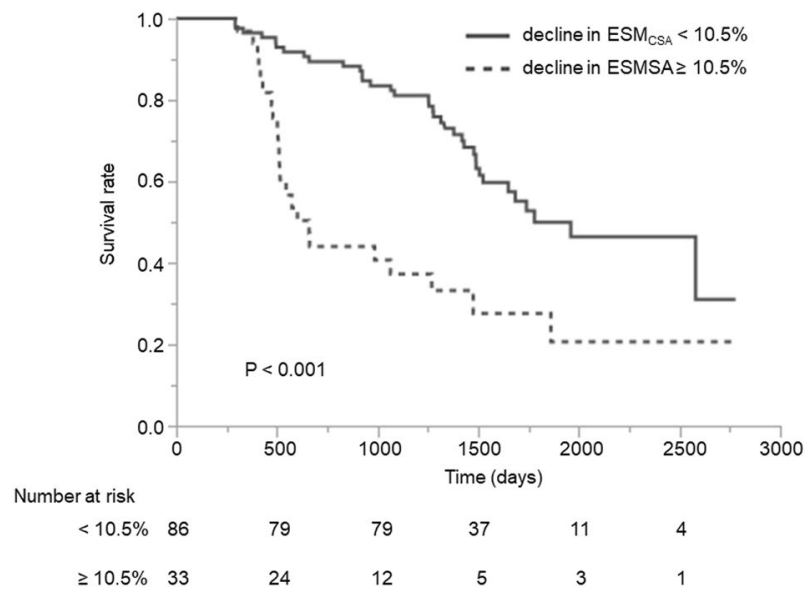

Figure 3. Kaplan-Meier curves and log-rank test. Kaplan-Meier survival curves stratified by the relative decline in $\mathrm{ESM}_{\mathrm{CSA}}$ at 6 months $(\mathrm{n}=119)$. The cutoff value was set at $10.5 \%$. The patients with a relative decline in $\mathrm{ESM}_{\mathrm{CSA}}$ more than $10.5 \%$ had significantly poorer survival $(\mathrm{P}<0.001$ by log-rank test).

factor, while the relative decline BMI (HR 1.036, 95\% CI 0.986-1.088, P =0.163) and the relative decline in \%FVC (HR 1.021, 95\% CI 0.992-1.050, $\mathrm{P}=0.155$ ) were not.

HRs and 95\% CI for each parameter on uni- and multivariate Cox regression analyses in the baseline cohort $(\mathrm{n}=144)$ are shown in Supplemental Table 3.

Kaplan-Meier curves, log-rank tests and number at risk. Kaplan-Meier curves of the cohort available for 6 months of follow-up $(n=119)$ are shown in Fig. 3. To determine an optimal cutoff value for predicting 3-year mortality, we constructed receiver operator characteristic (ROC) analysis. A cutoff value of $10.5 \%$ (AUC $=0.734$, specificity: 0.752 , sensitivity: 0.553 ) was identified. The median survival times were as follows: the relative decline in $\mathrm{ESM}_{\mathrm{CSA}} \geq 10.5 \%, 602$ [480-1269] days; the relative decline in $\mathrm{ESM}_{\mathrm{CSA}}<10.5 \%, 1431$ [1130$1743]$ days. The relative decline in $\mathrm{ESM}_{\mathrm{CSA}} \geq 10.5 \%$ had a significantly poorer prognosis $(\mathrm{P}<0.001, \log$-rank test $)$.

Characteristics with IPF patients with or without ESM $_{\mathrm{CSA}}$ decline. The clinical characteristics of patients with IPF with $(\geq 10.5 \%)$ or without $(<10.5 \%)$ ESM $_{\mathrm{CSA}}$ decline are shown in Table 4 . There were significant difference in baseline BMI $(\mathrm{P}=0.049)$, baseline $\% \mathrm{FVC}(\mathrm{P}=0.002)$, baseline forced expiratory volume in 1 second $\left(\mathrm{FEV}_{1}\right) / \mathrm{FVC}(\mathrm{P}=0.002)$, baseline lowest $\mathrm{SpO}_{2}$ during $6 \mathrm{MWT}(\mathrm{P}=0.004), \mathrm{ESM}_{\mathrm{CSA}}$ after 6 months $(\mathrm{P}<0.001)$, survival time $(\mathrm{P}<0.001)$, the relative decline in $\mathrm{ESM}_{\mathrm{CSA}}(\mathrm{P}<0.001)$, the relative decline in \%FVC $(\mathrm{P}=0.003)$, the relative decline in $\% \mathrm{DL}_{\mathrm{CO}}(\mathrm{P}=0.004)$ and the relative decline in $\mathrm{BMI}(\mathrm{P}<0.001)$. During the 6 months, there were 7 unexpected hospitalisations ( 3 acute exacerbations, 2 infections and 2 instances of worsening IPF). Pirfenidone was prescribed to 28 patients during the 6 months whereas nintedanib was prescribed to none (Table 4). The number of cancer and chronic heart failure comorbidities, as well as, the Charlson comorbidity index of the study population, are also shown in Table 4. 


\begin{tabular}{|c|c|c|c|}
\hline Variable & $\begin{array}{l}\text { With } \mathrm{ESM}_{\mathrm{CSA}} \\
\text { decline }(\geq 10.5 \%)\end{array}$ & $\begin{array}{l}\text { Without } \text { ESM }_{\text {CSA }} \\
\text { decline }(<\mathbf{1 0 . 5} \%)\end{array}$ & P-value \\
\hline Total, n & 33 & 86 & \\
\hline Age, years & $65.0[60.0-71.0]$ & $67.0[62.0-70.8]$ & 0.744 \\
\hline Sex, Female, n (\%) & $6(18.2 \%)$ & $15(17.4 \%)$ & \\
\hline Baseline body mass index, $\mathrm{kg} / \mathrm{m}^{2}$ & $22.6[21.5-24.1]$ & $24.0[21.8-26.0]$ & 0.049 \\
\hline Baseline FVC, $\%$ predicted, $\%$ & $73.0[64.9-86.6]$ & $87.2[72.7-99.7]$ & 0.002 \\
\hline Baseline $\mathrm{FEV}_{1} / \mathrm{FVC}, \%$ & $89.7[84.8-94.0]$ & $85.5[79.1-89.2]$ & 0.002 \\
\hline Baseline $\mathrm{DL}_{\mathrm{CO}}, \%$ predicted, $\%$ & $60.0[43.6-76.8]$ & $60.8[49.4-76.5]$ & 0.690 \\
\hline Baseline distance walked during 6MWT, m & $558[482-627]$ & $593[536-649]$ & 0.123 \\
\hline Baseline lowest $\mathrm{SpO}_{2}$ during $6 \mathrm{MWT}, \%$ & $80.0[77.0-86.5]$ & $87.0[82.0-90.0]$ & 0.004 \\
\hline Baseline $\mathrm{ESM}_{\mathrm{CSA}}, \mathrm{cm}^{2}$ & $34.2[28.2-37.5]$ & $34.3[27.3-40.7]$ & 0.495 \\
\hline $\mathrm{ESM}_{\mathrm{CSA}}$ after 6 months, $\mathrm{cm}^{2}$ & $27.4[23.5-31.5]$ & $33.6[27.4-39.5]$ & $<0.001$ \\
\hline Survival time, day & $602[480-1269]$ & $1430[1130-1743]$ & $<0.001$ \\
\hline Death during observation period, n (\%) & $23(69.7 \%)$ & $36(41.9 \%)$ & \\
\hline Relative decline in $\mathrm{ESM}_{\mathrm{CSA}}, \%$ & $15.7[13.9-21.8]$ & $3.0[-2.2-6.9]$ & $<0.001$ \\
\hline Relative decline in \%FVC, \% & $4.0[-1.5-12.8]$ & $0.3[-3.5-4.1]$ & 0.003 \\
\hline Relative decline in \%DLCO, \% & $6.4[2.1-14.5]$ & $1.4[-4.2-7.8]$ & 0.004 \\
\hline Relative decline in body mass index, $\%$ & $3.2[-1.0-10.5]$ & $-0.1[-3.3-2.2]$ & $<0.001$ \\
\hline Corticosteroid treatment, $\mathrm{n}(\%)$ & $5(15.2 \%)$ & $6(7.0 \%)$ & \\
\hline Pirfenidone treatment, n (\%) & $12(35.3 \%)$ & $16(18.6 \%)$ & \\
\hline Hospitalisation during 6 months, n (\%) & $4(12.1 \%)$ & $3(3.5 \%)$ & \\
\hline Acute exacerbations, $\mathrm{n}(\%)$ & $0(0 \%)$ & $3(3.5 \%)$ & \\
\hline Infections, $\mathrm{n}(\%)$ & $2(6 \%)$ & $0(0 \%)$ & \\
\hline Worsening of IPF & $2(6 \%)$ & $0(0 \%)$ & \\
\hline Charlson comorbidity index & $1.0[1.0-1.0]$ & $1.0[1.0-1.0]$ & \\
\hline Chronic heart failure, $\mathrm{n}(\%)$ & $2(6 \%)$ & $2(6 \%)$ & \\
\hline Cancers, $\mathrm{n}(\%)$ & $1(3 \%)$ & $2(6 \%)$ & \\
\hline
\end{tabular}

Table 4. Characteristics with IPF patients with or without $\mathrm{ESM}_{\mathrm{CSA}}$ decline. Data are presented as median [interquartile range] or $\mathrm{n}(\%)$. Abbreviations: ESMCSA, cross-sectional area of elector spine muscles; FVC, forced vital capacity: FEV1, forced expiratory volume in 1.0 second; DLCO, diffuse capacity of the lung for carbon monoxide; 6MWT; 6-minute walk test, SpO2; percutaneous oxygen saturation, IPF, idiopathic pulmonary fibrosis. *We analysed using $\mathrm{n}=114$, because 5 cases were missing.

Decline in $\mathrm{ESM}_{\mathrm{CSA}}$ and effects of treatment with corticosteroids. No patients had been treated with corticosteroids at baseline, but 11 patients were treated with corticosteroids 6 months later. We compared the relative decline in $\mathrm{ESM}_{\mathrm{CSA}}$ between the patients treated with corticosteroids and those who were not. In the patients treated with corticosteroids, the relative decline in $\mathrm{ESM}_{\mathrm{CSA}}$ was 9.6 [3.5-16.8] \% after 6 months. In the patients not treated with corticosteroids, the relative decline in $\mathrm{ESM}_{\mathrm{CSA}}$ was $6.0[-0.2-10.6] \%$ after 6 months. There was no statistical difference $(\mathrm{P}=0.096)$ between the two groups (Wilcoxon rank-sum test).

\section{Discussion}

Baseline $\mathrm{ESM}_{\mathrm{CSA}}$ is a prognostic factor in patients with $\mathrm{IPF}^{22,24}$. Here, we demonstrated that the serial change in $\mathrm{ESM}_{\mathrm{CSA}}$ is also a prognostic factor in patients with IPF. On multivariate analysis, the decline in $\mathrm{ESM}_{\mathrm{CSA}}$ was a significant prognostic factor, while those of predicted \%FVC and BMI were not.

It is widely known that the decline in FVC is a strong prognostic factor ${ }^{15,16}$. Measurements of serial changes in $\mathrm{FVC}$ are used as a gold standard in clinical trials ${ }^{25-28}$. Interestingly, in the present study, the decline in $\mathrm{ESM}_{\mathrm{CSA}}$ (HR 1.039, 95\% CI 1.007-1.071, $\mathrm{P}=0.015$ ) was a significant prognostic factor in the multivariate analyses, while the decline in \%FVC was not. This result may indicate that the decline in $\mathrm{ESM}_{\mathrm{CSA}}$ is a stronger prognostic factor than the decline in \%FVC. The decline in $\mathrm{ESM}_{\mathrm{CSA}}$ was correlated with the decline in \%FVC. However, the decline in $\mathrm{ESM}_{\mathrm{CSA}}(6.2[0.5-11.8] \%)$ was significantly greater than that in \%FVC $(1.4[-3.1-5.0] \%)$. It is possible that this result influences the data of multivariate Cox-proportion analysis. We did not evaluate the results of 6MWT because the missing data of 6 months later were not small. Further studies are needed to verify whether the decline in $\mathrm{ESM}_{\mathrm{CSA}}$ is useful for predicting mortality as compared with serial changes in the lowest $\mathrm{SpO}_{2}$ and the distance walked during the 6MWT.

Cachexia and sarcopenia have been extensively studied in patients with lung cancer and COPD. Evan's diagnostic criteria for cachexia include evaluation items such as muscle mass, fatigue and weight loss. In an attempt to include a wider evaluation of the burden of cachexia, diagnostic criteria based on an assessment of laboratory data and symptoms in addition to weight have been proposed ${ }^{17}$. The criteria included weight loss $\geq 5 \%$ in 12 months or low BMI $\left(<20 \mathrm{~kg} / \mathrm{m}^{2}\right)$ with 3 of 5 of the following features: decrease muscle strength, fatigue, anorexia, low fat-free mass index, of abnormal biochemistry (increased inflammatory markers, anaemia and low serum albumin). We reason that cachexia would be associated with the survival in IPF. 
Kinsey et al. reported that a smaller pectoralis muscle area, as measured on CT images obtained at the time of diagnosis of non-small cell lung cancer, was associated with poorer overall survival ${ }^{29}$. McDonald et al. reported that patients with a smaller pectoralis muscle area on CT scan tended to have a more severe expiratory air flow obstruction, lower quality of life scores and diminished exercise capacity, as compared with people with a lower $\mathrm{BMI}^{30}$. The measurement of the psoas muscle at the L3 or L4 level on CT images is frequently used for evaluating sarcopenia ${ }^{31}$. Canvasser et al. reported a strong correlation between the paraspinous muscle area at Th12 and the total psoas area at $\mathrm{L} 4(\mathrm{r}=0.72, \mathrm{P}<0.001)$, and both were associated with lower mortality rates after surgery ${ }^{32}$. Those authors suggest that measuring the area of the erector spinae muscles at the Th12 level might be useful for evaluating skeletal muscles in patients with lung disease who have not undergone an abdominal CT. However, no data on the pectoralis muscles exist in patients with IPF presently. In patients with IPF, chest CT scans are regularly taken in clinical practice, along with chest X-rays and pulmonary function tests. Based on these and our results, measuring erector spinae muscles (ESMs) by chest CT images would be useful in evaluating sarcopenia and cachexia in patients with IPF.

Loss of skeletal muscle mass is considered to be induced by systemic inflammation, inactivity, malnutrition and enhanced energy expenditure ${ }^{17-20}$. In the present study, the decline in ESM $_{\mathrm{CSA}}$ was weakly correlated with the decline in BMI $(\mathrm{r}=0.394$ [0.2170.552], $\mathrm{P}<0.001)$, baseline lowest $\mathrm{SpO}_{2}$ during $6 \mathrm{MWT}(\mathrm{r}=-0.290$ $[-0.458-0.101], \mathrm{P}=0.002)$, baseline \%FVC $(\mathrm{r}=-0.285[-0.464--0.089], \mathrm{P}=0.002)$ and the decline in \%FVC $(\mathrm{r}=0.202$ [0.0220.358], $\mathrm{P}=0.028)$. In a previous report, $\mathrm{ESM}_{\mathrm{CSA}}$ was weakly correlated with percentage of predicted $\mathrm{FEV}_{1}(\mathrm{r}=0.31, \mathrm{P}<0.0004)$ in patients with $\mathrm{COPD}^{21}$. Impaired pulmonary function, exercise-induced hypoxemia and nutrition status might influence the decline in $\mathrm{ESM}_{\mathrm{CSA}}$. However, further studies are needed to understand the mechanisms underlying muscle loss in IPF.

Only 11 patients were treated with corticosteroids in this study, and there was no significant difference in the decline in $\mathrm{ESM}_{\mathrm{CSA}}$. However, we cannot rule out the possibility that muscle atrophy due to the side effects of corticosteroids affected the $\mathrm{ESM}_{\mathrm{CSA}}$. Further studies are needed to explore this possibility. Moreover, the influence of appetite loss side effects of anti-fibrotic drugs on the $\mathrm{ESM}_{\mathrm{CSA}}$ should be investigated in future studies.

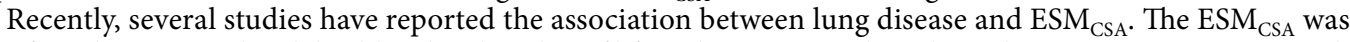
significantly associated with health-related quality of life and prognostic physiological parameters in patients with Mycobacterium avium complex lung disease ${ }^{33}$. A smaller ESM $_{\mathrm{CSA}}$ was significantly associated with a lower level of activities of daily living at the end of treatment for pneumonia ${ }^{34}$.

The present study has the following limitations. First, in the study, the results were obtained by a retrospective analysis of all Japanese patients from a single centre. The sample size was small and there was no replication cohort. Further studies are required to confirm our observations in other external validation cohorts. Second, the diagnoses of IPF were according to the 2011 international guideline. The diagnosis of patients who initially presented before 2011 was confirmed by MDD according to the 2011 guidelines. In these patients, the diagnosis may be more accurate due to a consideration of the MDD time course. The limitation is that the MDD diagnosis before and after 2011 may not be the same. Third, 25 of 144 patients (17.4\%) were not available for CT images to compare the changes at 6 months. Eleven patients died within 6 months, and CT images of the rest of the patients were not available for several reasons. Fourth, in the present study, approximately $16.7 \%$ (30 of 180 patients) of the CT of patients with IPF excluded the 12th thoracic spinous process level. This might be because the lungs of patients with IPF are smaller than those with COPD. This is another limitation of the present study. Fifth, we did not adjust for treatment in the survival analysis. The reason was that there was bias because a little evidence in anti-fibrotic drugs for IPF existed before 2014.

In conclusion, we have demonstrated that a smaller $\mathrm{ESM}_{\mathrm{CSA}}$ is a prognostic predictor in patients with IPF. A reduced $\mathrm{ESM}_{\mathrm{CSA}}$ after 6 months was an independent prognostic predictor in patients with IPF.

\section{Methods}

This single centre retrospective study was performed in accordance with the amended Declaration of Helsinki. The ethical review board of Tosei General Hospital, which contributed cases to this study, provided approval for the study (approval number 745). The study was also approved by the ethical review board of the Nagoya City University Hospital (approval number 60-18-0210), where the CT analyses were performed. Given that the data were analysed anonymously, the ethical review boards did not ask for the patients' approval or informed consent. The opt-out document can be found on the website of Tosei General Hospital.

Patients. During the period of June 2008 to July 2013, the clinical records of 180 consecutive patients with IPF, referred to the Tosei General Hospital without corticosteroid or anti-fibrotic drug pre-treatments, were retrospectively reviewed. IPF was diagnosed by multidisciplinary discussion (MDD) according to 2011 international guidelines $^{1}$. The diagnosis of patients who initially presented before 2011 was confirmed by MDD according to the 2011 guidelines before May 2015.

The following patients were excluded: one patient, who experienced acute exacerbations at the initial visit; patients who had other comorbidities, such as lung cancer $(n=1)$, infectious diseases or congested cardiac failure at the initial presentation; thirty patients, whose chest CT lacked the level of the spinous process of the 12th thoracic vertebrae and four patients, who underwent lung transplantation because due to the small number of patients and the consideration of death and lung transplantation as different outcomes.

Ultimately a total of 144 patients were enrolled. After approximately 6 months, Chest CT images were available for 119 patients. The interval between performing the CT at baseline and the second time was 190 [169-217] days.

Besides, the duration between the day of performing the chest CT on the first visit to the last visit or death was recorded. Other cases were contacted to confirm their life-or-death status by telephone. 
(A)

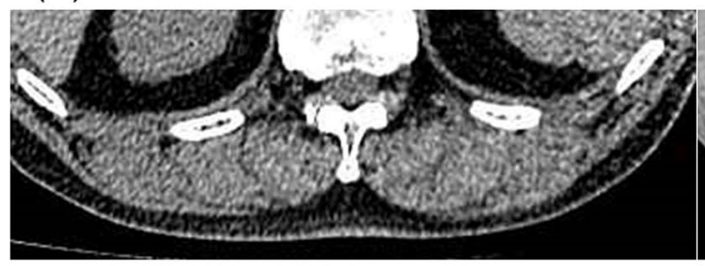

(C)
(B)

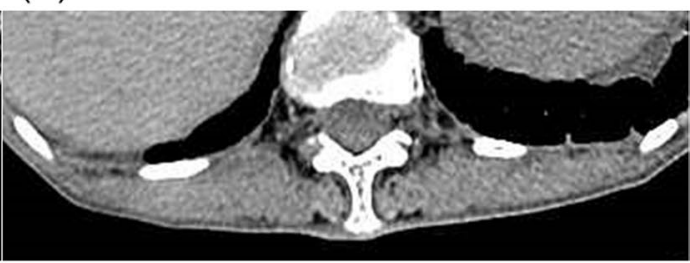

(D)

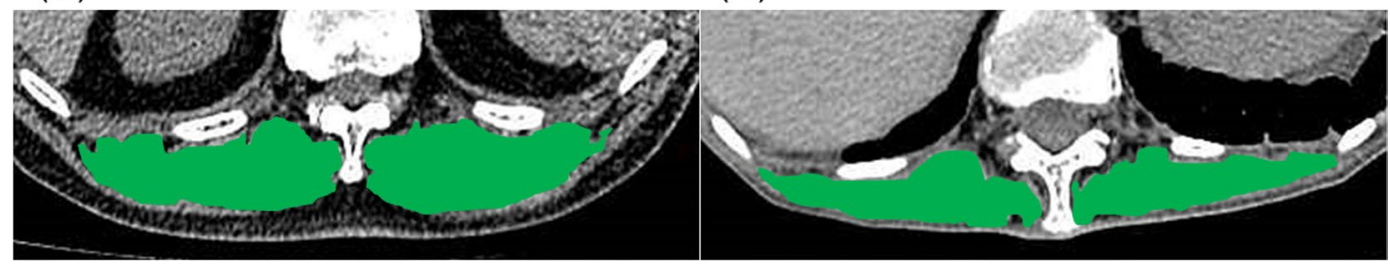

Figure 4. The cross-sectional area of the erector spinae muscles. Representative computed tomographic images used to measure the cross-sectional area of the erector spinae muscles $(\mathbf{A}, \mathbf{B})$. The cross-sectional areas of the erector spinae muscles are in green $(\mathbf{C}, \mathbf{D})$. The sums of the areas of the erector spinae muscles were $55.8 \mathrm{~cm}^{2}$ $(\mathbf{A}, \mathbf{C})$, and $14.9 \mathrm{~cm}^{2}(\mathbf{B}, \mathbf{D})$.

Computed tomography. All patients underwent CT scan using a commercially available CT scanner (Aquilion, Toshiba Medical Systems, Tokyo, Japan) with a high-frequency algorithm. HRCT images were obtained without intravenous contrast and with the patient in the supine position at full inspiration. HRCT images with $0.5-\mathrm{mm}$-thick slices at $0.5-\mathrm{mm}$ intervals were used for the analysis.

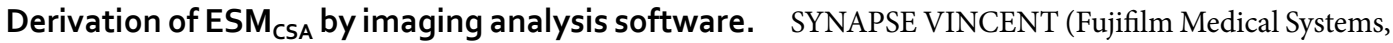
Tokyo, Japan) CT imaging analysis software was used for the derivation of $\mathrm{ESM}_{\mathrm{CSA}}$. $\mathrm{ESM}_{\mathrm{CSA}}$ was calculated manually according to a previously published method ${ }^{21}$. Briefly, ESM $_{\mathrm{CSA}}$ was measured on a single-slice axial CT image at the level of the spinous process of the 12th thoracic vertebra. For the quantitative analysis of the ESMs, chest HRCT images were reconstructed using the mediastinal window settings (window level, $40 \mathrm{HU}$; window width, $300 \mathrm{HU}$ ). The left and right ESMs were identified and manually shaded and the ESM area was reported as the sum of the right and left ESMs. All CT analyses were independently performed by trained individuals (ANa and HO) who were blinded to the patients' clinical information. The average values of $\mathrm{ESM}_{\mathrm{CSA}}$ of $\mathrm{ANa}$ and $\mathrm{HO}$ were used in this study. Figure 4 shows the images of the $\mathrm{ESM}_{\mathrm{CSA}}$ in two patients with IPF. The correlation of the values of $\mathrm{ESM}_{\mathrm{CSA}}$ between trained individuals and the agreement of two individuals were analysed using the Spearman's correlation test and the Bland-Altman analysis, respectively.

Pulmonary function tests and six-minute walk test. All patients underwent pulmonary function tests by spirometry (CHESTAC-55 V; Chest, Tokyo, Japan), according to the American Thoracic Society and European Respiratory Society (ATS/ERS) criteria ${ }^{35}$. The $\mathrm{DL}_{\mathrm{CO}}$ was also measured (CHESTAC-55 V). The values of FVC, $\mathrm{FEV}_{1}$ and $\mathrm{DL}_{\mathrm{CO}}$ were measured according to ATS/ERS recommendations ${ }^{36}$. We calculated $\% \mathrm{FEV}_{1}, \% \mathrm{FVC}$ and $\% \mathrm{DL}_{\mathrm{CO}}$ based on the patients' height, age and sex per the Japanese guidelines ${ }^{37}$. We then conducted $6 \mathrm{MWTs}$ without supplemental oxygen in accordance with ATS guidelines ${ }^{38}$.

The comorbidities and the Charlson comorbidity index. The Charlson comorbidity index was calculated according to a previously reported $\operatorname{method}^{39}$.

Statistical analyses. Continuous variables were presented as medians and interquartile ranges. Categorical variables were presented as numbers and percentages. The differences between patients who underwent HRCT after 6 months and those who did not were analysed using the Student's t-test or the Wilcoxon rank-sum test. Spearman's rank correlation coefficients were used to test for correlations between SSM $_{\mathrm{CSA}}$ and clinical parameters and those between the relative decline in $\mathrm{ESM}_{\mathrm{CSA}}$ and clinical parameters. Univariate and multivariate Cox regression analyses were performed to evaluate the relationship between each variable and mortality. We included factors with $\mathrm{P}$-values $<0.05$ in the univariate analysis for the multivariate analyses. Survival times were estimated using the Kaplan-Meier method and compared with the log-rank test. To determine the optimal cutoff value for predicting 3-year mortality, we constructed ROC curves. P-values less than 0.05 were considered significant. The statistical analyses were conducted using JMP statistical software (version 14; SAS Institution Japan Ltd, Japan). Since we could not analyse the $\mathrm{r}(95 \% \mathrm{CI})$ with JMP statistical software (version 14), we analysed r (95\%CI) using SPSS (version 26; IBM, Japan).

Received: 6 August 2019; Accepted: 22 January 2020;

Published online: 11 February 2020 


\section{References}

1. Raghu, G. et al. An official ATS/ERS/JRS/ALAT statement: idiopathic pulmonary fibrosis: evidence-based guidelines for diagnosis and management. Am. J. Respir. Crit. Care Med. 183, 788-824 (2011).

2. Lederer, D. J. \& Martinez, F. J. Idiopathic pulmonary fibrosis. N. Engl. J. Med. 378, 1811-1823 (2018).

3. Ley, B. et al. A multidimensional index and staging system for idiopathic pulmonary fibrosis. Ann. Intern. Med. 156, 684-691 (2012).

4. Natsuizaka, M. et al. Epidemiologic survey of Japanese patients with idiopathic pulmonary fibrosis and investigation of ethnic differences. Am. J. Respir. Crit. Care Med. 190, 773-779 (2014).

5. Sumikawa, H. et al. Computed tomography findings in pathological usual interstitial pneumonia: relationship to survival. Am. J. Respir. Crit. Care Med. 177, 433-439 (2008).

6. Enomoto, N. et al. Amount of elastic fibers predicts prognosis of idiopathic pulmonary fibrosis. Respir. Med. 107, 1608-1616 (2013).

7. Harada, T., Watanabe, K., Nabeshima, K., Hamasaki, M. \& Iwasaki, H. Prognostic significance of fibroblastic foci in usual interstitial pneumonia and non-specific interstitial pneumonia. Respirology. 18, 278-283 (2013).

8. Tajiri, M. et al. Serum level of periostin can predict long-term outcome of idiopathic pulmonary fibrosis. Respir. Investig. 53, 73-81 (2015).

9. Song, J. W. et al. Blood biomarkers MMP-7 and SP-A: predictors of outcome in idiopathic pulmonary fibrosis. Chest. 143, 1422-1429 (2013).

10. Furukawa, T. et al. The St. George's Respiratory Questionnaire as a prognostic factor in IPF. Respir. Res. 18, 18 (2017).

11. Oda, K. et al. High-resolution CT scoring system-based grading scale predicts the clinical outcomes in patients with idiopathic pulmonary fibrosis. Respir Res. 15, 10 (2014).

12. Ohkubo, H. et al. A volumetric computed tomography analysis of the normal lung in idiopathic pulmonary fibrosis: The relationship with the survival. Intern. Med. 57, 929-937 (2018).

13. Ohkubo, H., Nakagawa, H. \& Niimi, A. Computer-based quantitative computed tomography image analysis in idiopathic pulmonary fibrosis: A mini review. Respir Investig. 56, 5-13 (2018).

14. Teramachi, R. et al. Progression of mean pulmonary arterial pressure in idiopathic pulmonary fibrosis with mild to moderate restriction. Respirology. 22, 986-990 (2017).

15. Zappala, C. J. et al. Marginal decline in forced vital capacity is associated with a poor outcome in idiopathic pulmonary fibrosis. Eur. Respir. J. 35, 830-836 (2010).

16. Paterniti, M. O. et al. Acute exacerbation and decline in forced vital capacity are associated with increased mortality in idiopathic pulmonary fibrosis. Ann. Am. Thorac. Soc. 9, 1395-1402 (2017).

17. Evans, W. J. et al. Cachexia: a new definition. Clin. Nutr. 27, 793-799 (2008).

18. Morley, J. E., Thomas, D. R. \& Wilson, M. M. Cachexia: pathophysiology and clinical relevance. Am. J. Clin. Nutr. 83, 735-743 (2006).

19. Durham, W. J., Dillon, E. L. \& Sheffield-Moore, M. Inflammatory burden and amino acid metabolism cancer cachexia. Curr. Opin. Clin. Nutr. Metab. Care. 12, 72-77 (2009).

20. Cruz-Jentoft, A. J. et al. European Working Group on Sarcopenia in Older People. Sarcopenia: European consensus on definition and diagnosis. Report of the European Working Group on Sarcopenia in older people. Age Aging. 39, 412-423 (2010).

21. Tanimura, K. et al. Quantitative assessment of erector spinae muscles in patients with chronic obstructive pulmonary disease. Novel chest computed tomography-derived index for prognosis. Ann. Am. Thorac. Soc. 13, 334-341 (2016).

22. Suzuki, Y. et al. Distinct profile and prognostic impact of body composition changes in idiopathic pulmonary fibrosis and idiopathic pleuroparenchymal fibroelastosis. Sci. Rep. 8, 14074 (2018).

23. Miller, J. A. et al. Sarcopenia is a predictor of outcomes after lobectomy. J. Thorac. Dis. 10, 432-440 (2018).

24. Moon, S. W. et al. Thoracic skeletal muscle quantification: low muscle mass is related with worse prognosis in idiopathic pulmonary fibrosis patients. Respir. Res. 20, 35 (2019).

25. Richeldi, L. et al. INPULSIS Trial Investigators: Efficacy and safety of nintedanib in idiopathic pulmonary fibrosis. N. Engl. J. Med. 370, 2071-2082 (2014).

26. King, T. E. Jr. et al. ASCEND Study Group: A phase 3 trial of pirfenidone in patients with idiopathic pulmonary fibrosis. N. Engl. J. Med. 370, 2083-2092 (2014).

27. Lederer, D. J. et al. Sensitivity Analyzes of the change in FVC in a Phase 3 Trial of Pirfenidone for idiopathic pulmonary fibrosis. Chest. 148, 196-201 (2018).

28. du Bois, R. M. et al. Forced vital capacity in patients with idiopathic pulmonary fibrosis: test properties and minimal clinically important difference. Am. J. Respir. Crit. Care Med. 184, 1382-1389 (2011).

29. Kinsey, C. M. et al. Lower pectoralis muscle area is associated with worse overall survival in non-small cell lung cancer. Cancer Epidemiol. Biomarkers Prev. 26, 38-43 (2017).

30. McDonald, M. L. et al. Quantitative computed tomography measures of pectoralis muscle area and disease severity in chronic obstructive pulmonary disease. A cross-sectional study. Ann. Am. Thorac. Soc. 11, 326-334 (2014).

31. Boutin, R. D., Yao, L., Canter, R. J. \& Lenchik, L. Sarcopenia: Current concepts and imaging implications. AJR Am. J. Roentgenol. 205, W255-266 (2015).

32. Canvasser, L. D. et al. Paraspinous muscle as a predictor of surgical outcome. J. Surg. Res. 192, 76-81 (2014).

33. Asakura, T. et al. Quantitative assessment of erector spinae muscles in patients with Mycobacterium avium complex lung disease. Respir. Med. 145, 66-72 (2018).

34. Minegishi, Y. et al. Smaller erector spinae muscle size is associated with inability to recover activities of daily living after pneumonia treatment. Respir. Investig. 57, 191-197 (2019).

35. Laszlo, G. Standardisation of lung function testing: helpful guidance from the ATS/ERS Task Force. Thorax. 61, 744-746 (2006).

36. Macintyre, N. et al. Standardisation of the single-breath determination of carbon monoxide uptake in the lung. Eur Respir J. 26, 720-735 (2005).

37. Sasaki, E., Nakamura, M. \& Kida, K. [Reference values for spirogram and blood gas analysis in Japanese non-smoking healthy adults] [in Japanese]. Nihon Kokyuki Gakkai Zassi 39, S1-S17 (2001).

38. ATS Committee on Proficiency Standards for Clinical Pulmonary Function Laboratories. ATS statement: guidelines for the sixminute walk test. Am. J. Respir. Crit. Care Med. 166, 111-117 (2002).

39. Quan, H. et al. Updating and validating the Charlson comorbidity index and score for risk adjustment in hospital discharge abstracts using data from 6 countries. Am. J. Epidemiol. 2173, 676-82 (2011).

\section{Acknowledgements}

The authors would like to thank Enago (www.enago.jp) for the English language review.

\section{Author contributions}

A.Na. and H.O. equally contributed to the study. A.Na. and H.O. drafted the submitted article and were responsible for the integrity of the data and the accuracy of the data analysis. Y.Ka. and A.Ni. contributed to the study design, and interpretation of the manuscript. H.T., Y.Ko., T.M., M.Y. and T.F. contributed to the study design, data accumulation and interpretation of the manuscript. 


\section{Competing interests}

The authors declare no competing interests.

\section{Additional information}

Supplementary information is available for this paper at https://doi.org/10.1038/s41598-020-59100-5.

Correspondence and requests for materials should be addressed to H.O.

Reprints and permissions information is available at www.nature.com/reprints.

Publisher's note Springer Nature remains neutral with regard to jurisdictional claims in published maps and institutional affiliations.

(c) (i) Open Access This article is licensed under a Creative Commons Attribution 4.0 International License, which permits use, sharing, adaptation, distribution and reproduction in any medium or format, as long as you give appropriate credit to the original author(s) and the source, provide a link to the Creative Commons license, and indicate if changes were made. The images or other third party material in this article are included in the article's Creative Commons license, unless indicated otherwise in a credit line to the material. If material is not included in the article's Creative Commons license and your intended use is not permitted by statutory regulation or exceeds the permitted use, you will need to obtain permission directly from the copyright holder. To view a copy of this license, visit http://creativecommons.org/licenses/by/4.0/.

(C) The Author(s) 2020 